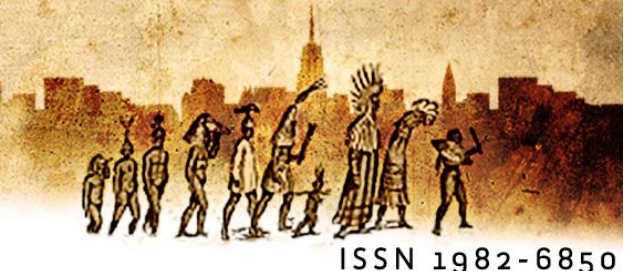

\title{
Representações de professores-formadores em textos produzidos sobre o seu trabalho
}

\author{
Alessandra Augusta Pereira da Silvai (UNESPAR) \\ Francini Percinoto Poliseli Corrêaii (UNESPAR) \\ Vera Lúcia Lopes Cristovãoiii (UEL)
}

\begin{abstract}
Resumo: Este artigo apresenta resultados parciais de duas pesquisas em nível de doutoramento que investigaram representações construídas em textos produzidos por professores-formadores em contexto de formação inicial em Letras quanto ao seu trabalho educacional. Utilizando a perspectiva teórico-metodológica do Interacionismo Sociodiscursivo e aportes teóricos das Ciências do Trabalho, as análises de dados gerados contribuem para ampliar a compreensão do trabalho docente.
\end{abstract}

Palavras-chave: professor-formador; trabalho docente; representações.

Abstract: This article aims at presenting partial results of two doctoral research works which investigated representations on educational work constructed in texts produced by teacher educators involved with pre-service teacher education in Letters. Based on the theoretical and methodological perspective of the Sociodiscursive Interactionism and the Work Sciences, the analyses of the data contribute to enlarge our comprehension of the teaching activity.

Key words: teacher educator; teaching activity; representations.

\section{Introdução}

Esse texto aborda duas pesquisas em nível de doutoramento que possuem várias características em comum: ambas estão em fase de conclusão e estão sendo desenvolvidas no Programa de Estudos da Linguagem, da Universidade Estadual de Londrina, assim como fazem parte do mesmo grupo de pesquisa situado nessa instituição - Linguagem e Educação - coordenado pela orientadora dessas investigações; as duas também estão sendo desenvolvidas na mesma instituição em que as pesquisadoras atuam como formadoras (UNESPAR), embora localizadas em diferentes campi (Apucarana e Campo Mourão). Além disto, tanto a pesquisa de Corrêa quanto a de Silva enfocam o trabalho de 
professores-formadores em um contexto de formação inicial em Letras e implicações deste na constituição profissional de alunos-professores. A motivação para o delineamento da pesquisa e a expectativa das formadoras em relação aos resultados alcançados também coincidem. Ambas objetivam possibilitar o desencadeamento de ações que possam contribuir para a formação de nossos alunos-professores e, eventualmente, melhor atuação destes na formação de crianças, jovens e/ou adultos.

Assim, o objetivo desse artigo é ampliar a compreensão do trabalho de formadores a partir de seus textos no e sobre o trabalho educacional. Ainda de grande relevância entre as convergências dessas duas pesquisas está o fato de que elas se alicerçam no mesmo referencial teórico metodológico para geração e análise de seus dados: o Interacionismo Sociodiscursivo, doravante ISD, (BRONCKART, 1999, 2006, 2008; MACHADO, 1995; CRISTOVÃO, 2002) em suas bases marxistas e vigotskianas e aliado a subsídios teóricos das Ciências do Trabalho. (AMIGUES, 2004; SAUJAT, 2002; 2004; FAÏTA, 2004; CLOT, 1999).

Embora essas pesquisas compartilhem desses elementos em comum, especialmente no que concerne ao enfoque no trabalho de professores-formadores que atuam na formação pré-serviço em Letras e no arcabouço teórico metodológico que sustenta suas análises, as trajetórias e o olhar para os dados gerados mediante os objetivos específicos de cada pesquisa as diferem notavelmente.

Dessa forma, procuramos apresentar os pressupostos teórico-metodológicos comuns destas duas pesquisas e, na sequência, apresentar a sua trajetória, objetivos específicos e alguns dos resultados alcançados.

\section{Pesquisas sobre o trabalho docente na perspectiva do ISD}

As bases epistemológicas que fundamentam a categoria trabalho em nossas pesquisas $^{1}$ são aquelas provenientes da corrente psicológica ou sociológica do ISD (BRONCKART, 1999, 2006, 2008; 2004; MACHADO, 1995; CRISTOVÃO, 2002) em suas bases marxistas e vigotskianas, além das contribuições das chamadas Ciências do Trabalho

\footnotetext{
${ }^{1}$ Essas pesquisas e respectivas propostas de análise linguístico-discursiva têm sido divulgadas em publicações pelos pesquisadores do grupo genebrino LAF e do Grupo de pesquisadores brasileiros - Grupo ALTER, da USP, coordenado pela Profa. Dra. Eliane Lousada, e outros, como: Linguagem e Educação, coordenado pela Profa. Dra. Vera Lúcia Lopes Cristovão; Gêneros textuais e Mediações Formativas - GEMFOR, sob a liderança da prof. Dra. Elvira Lopes Nascimento ou ainda as pesquisas realizadas na Paraíba - UFPB (PROLING),em especial, as desenvolvidas pelas Profa. Dra. Betânia Passos Medrado e Profa. Dra. Regina Celi Mendes Pereira, integrantes do Grupo de Estudos em Letramentos, Interação e Trabalho- GELIT- CNPq.
} 
(Ergonomia da Atividade -AMIGUES, 2004; SAUJAT, 2002 e 2004; Psicologia do Trabalho FAÏTA, 2004; CLOT, 1999).

Tendo suas origens alicerçadas no Interacionismo Social, o ISD tem especial interesse pela análise do agir comunicativo verbal, dado o papel fundamental que esta atribui à linguagem no desenvolvimento humano (BRONCKART, 1999, 2006, 2008).

Assim, configurando-se como uma Ciência do Humano, os procedimentos de análise do ISD constituem-se pluridisciplinarmente, uma vez que são consideradas contribuições de áreas/disciplinas diversas que se alicerçam nos "preceitos defendidos por Bakhtin, Volochínov e Vigotski com relação à dimensão social da linguagem e a sua importância para a emergência e o funcionamento do pensamento consciente humano. Além disto, o ISD se filia às perspectivas de análise que adotam "uma abordagem marxiana de trabalho, vigotskiana do desenvolvimento e/ou sociodiscursiva da linguagem". (MACHADO et al., 2004). É justamente devido a essa ancoragem pluridisciplinar, que os procedimentos teóricos metodológicos do ISD possibilitam uma reflexão mais abrangente das questões que envolvem a condição humana.

Ao buscar a compreensão do desenvolvimento humano, muitas dessas pesquisas têm focado o mundo do trabalho, especificamente o trabalho docente, e suas transformações. Segundo Bronckart e Machado (2004), a análise dos textos sobre a relação linguagem e trabalho pode trazer nova compreensão do trabalho do professor tanto em relação ao seu agir concreto quanto

[...] em relação às representações que socialmente se constroem sobre ele. Segundo Bronckart (1999), essas representações se constroem nas produções textuais, o que nos permite situar e julgar a contribuição de cada indivíduo para a realização de uma determinada atividade. Apropriadas e interiorizadas por esses mesmos indivíduos, elas acabam por se constituir em representações individuais, tornando-se uma espécie de guias para suas ações futuras. Daí a importância de analisar os textos - orais e escritos - ou a rede discursiva que se constrói no e sobre uma determinada atividade para chegar a compreender a natureza e as razões verbais e não verbais desenvolvidas e o papel que a linguagem aí desempenha (BRONCKART; MACHADO, 2004, p. 136).

Machado e Bronckart (2009, p. 35) defendem que "todos os textos produzidos (em situação de trabalho ou sobre o trabalho) se constituem como possíveis espaços de 
emergência" (de modelos de agir- morfogênese das ações) e "têm o poder de contribuir para a manutenção ou para a transformação desses modelos".

Como referencial teórico-metodológico, o ISD proporciona caminhos para a análise da linguagem. Analisamos não só os textos, mas também fatores determinantes de contexto, essenciais para a compreensão das práticas linguageiras. Assim, fazemos a análise em dois momentos distintos: a análise do contexto sociointeracional de produção dos textos e a análise linguístico-discursiva do texto. Os procedimentos metodológicos para análises de textos se configuram de forma descendente/ascendente (BRONCKART, 2006) ou seja, da análise do contexto para análises de unidades textuais menores e vice-versa, cabendo ao pesquisador, constantemente, o estabelecimento de relações entre o contexto sociointeracional de produção do texto e as escolhas linguísticas realizadas pelos seus enunciadores/produtores.

Particularmente, no que concerne à análise linguístico-discursiva, esses enunciados, materializados em textos de diversos gêneros, são analisados por suas "formas composicionais, a expressividade, as escolhas dos recursos lexicais e semânticos dos enunciados determinados pela interação e pela enunciação" (CRISTOVÃO; NASCIMENTO 2005, p. 44). Em outras palavras, a análise é realizada em seus níveis organizacional, enunciativo e semântico e, em cada um desses níveis, diferentes elementos são considerados. Neste texto, nos restringiremos a abordar recortes das análises de textos produzidos por formadores participantes das pesquisas de Corrêa e Silva em seu nível organizacional. Dentre outros elementos considerados para análise desse nível, apresentaremos, especificamente, análises quanto a determinados segmentos de organização temática (doravante SOT) e seus respectivos segmentos de tratamento temático (STT)² (MACHADO; BRONCKART, 2009) mobilizados pelas participantes quando da produção de seus textos no e sobre seu trabalho docente, paralelamente estabelecendo conexões com resultados de análises provenientes do contexto socioprofissional das produtoras dos textos.

\footnotetext{
2 Os segmentos de introdução de um tema são denominados por Bronckart (2008) de segmentos de orientação temática (SOT) e os segmentos que desenvolvem o tema efetivamente tratado, de segmentos de tratamento temático (STT).
} 


\subsection{Ampliando visões: o trabalho docente sob as lentes do ISD e das Ciências do Trabalho}

Nas obras marxianas, observamos a ratificação do trabalho como fundamento ontológico do mundo social. É a partir do trabalho que se dá a ruptura entre a dominação da natureza sobre o homem e ocorre, a partir disso, um salto ontológico, que implica, para Marx, um duplo movimento, pois, por um lado a natureza é transformada pelo homem e, por outro, o próprio homem se transforma. Marx expõe que,

Antes de tudo, o trabalho é um processo entre o homem e a natureza, um processo em que o homem, por sua própria ação, medeia, regula e controla seu metabolismo com a Natureza [...]. Ao atuar, por meio desse movimento, sobre a Natureza externa a ele e ao modificá-la, ele modifica, ao mesmo tempo, sua própria natureza (MARX, 2011, 149-150).

Assim, há a natureza, cujo ser humano depende para a produção e reprodução de sua vida, e o ser humano que ininterruptamente a transforma para satisfazer suas necessidades, a partir de objetivações que vão se exteriorizando e implicando novas possibilidades e necessidades, além de novos valores que vão atuar sobre as formas de trabalho.

O trabalho é a categoria fundante para Marx (2011), e isso não se trata do que veio primeiro, cronologicamente, mas o que determina os demais complexos. A linguagem surge no momento em que o trabalho se origina, bem como o pensamento e a sociabilidade, sendo considerados complexos universais por isso - esses são elementos fundamentais para a construção de uma ferramenta.

$\mathrm{Na}$ psicologia, Vigotski utiliza o termo instrumento para pesquisar o desenvolvimento das funções psíquicas superiores. Suas investigações são radicalmente baseadas nos estudos marxistas.

O ISD se apropria dos fundamentos teóricos trazidos por Vigotski, ao considerar "as ações humanas em suas dimensões sociais e discursivas constitutivas" (BRONCKART, 1999/2003/2007/2009, p.30-31) para a criação de uma unidade comum de análise da psicologia. Considerar as ações nessa perspectiva é considerar a evolução do ser humano no 
seu percurso histórico, não como ser natural, mas social, em que a aprendizagem e o desenvolvimento são conceitos nodulares.

Corroborar as concepções de aprendizagem e desenvolvimento concebidas por Vigotski (2009) implica compreender uma concepção voltada ao desenvolvimento filogenético do homem, em um primeiro momento, ao elaborar instrumentos para satisfazer suas necessidades de subsistência, mas, ao mesmo tempo, que se desenvolve como um ser cada vez mais social, ao passar a desenvolver as funções psíquicas superiores.

Nesse desenvolvimentlo, o instrumento, é sempre o produto histórico de uma sociedade dada: um instrumento entre o homem e seu objeto de trabalho ou entre o homem e outros homens (SCHNEUWLY, 2002, p. 02).

Com relação ao trabalho educacional exercido pelo professor na perspectiva do ISD, "O trabalho do professor consiste em transformar modos de pensar, de falar, de fazer com ajuda de ferramentas semióticas." (SCHNEUWLY, 2002, p. 23). Dessa forma, percebemos uma articulação profunda entre a discussão sobre ferramentas trazidas por Marx, instrumentos por Vigotski e Schneuwly para o desenvolvimento da perspectiva teóricametodológica do ISD.

No Brasil, Machado, (2004) esclarece que as pesquisas enfocando as relações entre linguagem e trabalho despontaram com o Grupo ATELIER (tendo como subgrupo o grupo ALTER) em 1996. Conforme nota 1, nos anos 2000 tais estudos, através do Grupo de pesquisadores brasileiros - LAEL, e do grupo genebrino LAF - as pesquisas passaram a considerar na análise do trabalho educacional contribuições das chamadas Ciências do Trabalho (Psicologia do Trabalho, Ergonomia da Atividade, Ergologia, etc.). Todos os envolvidos nestes grupos buscam "a construção de uma abordagem interdisciplinar sobre diferentes questões constitutivas do trabalho educacional" no intuito de contribuir para "o aprofundamento da compreensão do trabalho do professor e, consequentemente, da sua formação." (MACHADO, 2004, p. viii - ix).

Machado (2007), a partir de uma leitura marxiana da atividade de trabalho, juntamente com o precursor da perspectiva do ISD - Bronckart (1999/2003/2007/2009) e com estudiosos das Ciências do trabalho - Clot (2006) e Amigues (2004) adicionam à proposta de Schneuwly (2002) outros elementos constituintes do trabalho do professor (em 
sala de aula), quais sejam: o professor, o meio de trabalho, outrem e as ferramentas - que em sua concepção, podem se tornar instrumentos, caso sejam apropriados pelo docente.

A aprendizagem dos alunos deve ser vista como um objetivo a ser atingido em longo prazo, já que ela continuará a acontecer depois da vida escolar (AMIGUES, 2004). Assim, a análise do trabalho do professor não se configura apenas a partir do desempenho discente e/ou questões didáticas.

Machado (2007) explicita nove características do trabalho educacional que passa a ser entendido como uma atividade: 1. Situada - sofrendo a influência do contexto mais imediato e amplo; 2. Pessoal - considerando que engaja o professor nas mais variadas dimensões: cognitiva, física, emocional, etc.; 3. Impessoal- por não se desenvolver de forma totalmente livre, considerando que o professor segue prescrições que lhe são impostas; 4. Prefigurada - uma vez que o professor reelabora as prescrições que lhe são apresentadas, autoprescrevendo-se tarefas; 5 . Instrumentada - por ser mediada por instrumentos; 6. Interacional - na medida em que o professor age sobre o meio, transformando-o, com a utilização de instrumentos e é por eles transformado; 7 . Interpessoal - envolvendo os presentes na situação (alunos, por exemplo) e também ausentes (pais de alunos, por exemplo); 8. Conflituosa - porque o trabalhador é obrigado a fazer escolhas para direcionar seu agir, tentando transitar entre vozes contraditórias (prescrições, artefatos, outros envolvidos etc.); 9. (Pode ser) fonte - para a aprendizagem de novos conhecimentos e desenvolvimento de capacidades. (MACHADO, 2007, p.93/94).

Além dessas características, outros aspectos do trabalho de professores-formadores devem ser considerados, tais como a falta de infraestrutura dos cursos (falta de docentes, de acervo bibliográfico nas bibliotecas, de laboratório, etc.); o acúmulo de funções que precisam, por vezes, assumir, dentre elas: captador de recursos; técnico; produtor de textos científicos e de relatórios; executor de funções burocráticas. (FACCl et al., 2011). Dessa forma, defendemos que uma luta pela revalorização da atividade docente precisa se fortalecer em mais espaços da sociedade, a começar por ouvir o que o professor-formador tem a dizer sobre seu próprio trabalho. 
Nesse sentido, as duas pesquisas sucintamente apresentadas nesse artigo trazem como ponto central os textos produzidos por professores-formadores como uma reflexão sobre esse trabalho.

\section{O percurso das duas pesquisas}

\subsection{A primeira pesquisa: A perspectiva de professores-formadores sobre o seu trabalho educacional}

Concordando com Calvo (2013) quanto à incipiência de estudos que enfoquem o trabalho do formador de Letras, Corrêa estabelece como objetivo geral de sua pesquisa analisar como professoras-formadoras de um curso de Licenciatura em Letras/Inglês compreendem seu trabalho no contexto de formação inicial.

Para atingir esse objetivo geral a pesquisadora delimita seis objetivos específicos ${ }^{3}$, no entanto, neste artigo nos restringiremos a abordar somente os sujeitos de pesquisa, instrumentos de geração de dados, procedimentos de análise e resultados relacionados ao quinto objetivo específico desta pesquisa, qual seja, o de identificar desafios vivenciados pelas formadoras ao desenvolver seu trabalho educacional no contexto investigado

Coerente com a proposta teórico-metodológica do ISD e das Ciências do Trabalho, visando possibilitar a voz às docentes acerca de seu próprio ofício, dentre os instrumentos utilizados para geração de dados, este estudo desenvolve suas análises à partir de textos produzidos- relatos de experiência reflexivos e entrevista semiestruturada pelas 8 (oito) formadoras participantes responsáveis pelas disciplinas ministradas nos dois primeiros anos da primeira turma de um curso de Letras/Inglês em uma instituição pública de ensino superior. Tomando como fonte de dados primários os textos produzidos denominados relatos de experiência reflexivos e como fonte de dados secundários entrevistas

3 i) apontar particularidades quanto ao contexto sociossubjetivo/socioprofissional das formadoras participantes relacionando-as aos temas mobilizados por meio de seu agir linguageiro acerca de seu trabalho educacional; ii) inferir capacidades docentes que as formadoras acionam no desenvolvimento de seu trabalho educacional no contexto de formação inicial de professores em Letras/Inglês; iii) inferir capacidade (s) docente (s) que as formadoras evidenciam como necessárias para que seus alunos-professores desenvolvam durante o seu processo de formação inicial em Letras/Inglês; iv) apontar atividades/tarefas que as formadoras evidenciam utilizar/designar aos alunos-professores para propiciar o desenvolvimento de capacidade (s) docente (s) necessárias para o exercício da docência; v) identificar desafios vivenciados pelas formadoras ao desenvolver seu trabalho educacional no contexto investigado; vi) reconhecer o posicionamento das formadoras em relação às análises desenvolvidas. 
semiestruturadas, a análise linguístico-discursiva em nível organizacional quanto aos SOT e STT possibilitaram o levantamento de pelo menos 25 desafios vivenciados pelas formadoras participantes ao desenvolver seu trabalho educacional no contexto investigado, que foram agrupados pela pesquisadora em quatro grupos de STT, quais sejam:

Quadro 1: SOT Dificuldades/desafios enfrentados no desenvolvimento do trabalho educacional revelados nos relatos de experiência reflexivos.

\section{Grupo 1 - STT Relativos às dificuldades oriundas dos alunos-professores Atitudes negativas e/ou objetivos diversificados dos alunos-professores}

1) Resistência / incompreensão dos alunos quanto aos procedimentos/instrumentos didáticos pedagógicos adotados pela formadora;

2) Imaturidade;

3) Falta de comprometimento dos alunos;

4) Baixa auto estima;

5) Falta de confiança dos alunos na formadora;

6) Reclamações dos alunos sobre o curso como um todo;

7) Turma heterogênea em termos de objetivos ao frequentar o curso;

8) Cobrança dos alunos de resultados imediatos;

9) Pouco reconhecimento por parte dos alunos quanto aos resultados do processo de ensino/aprendizagem.

Deficiências de saberes mínimos

10) de habilidades/competências para fazer leituras críticas (LE e LM);

11) de habilidades/ competências linguísticas/discursivas/gramaticais para produção de textos/ gêneros acadêmicos;

12) em termos de proficiência linguística em LE em turmas heterogêneas;

13) de habilidades/competências linguísticas (compreensão oral em LE);

14) quanto à poesia (figuras de linguagem, aliteração, etc.).

Grupo 2: STT Relativos às dificuldades oriundas da própria formadora

Dificuldades ocasionadas pela falta de formação específica das formadoras

15) Falta de especialização específica na área.

Dificuldades ocasionadas pela necessidade de ações pontuais da formadora

16) Encontrar formas de avaliar o progresso real dos alunos;

17) Desenvolver atividades que tornem o ensino específico para professores;

18) Compatibilizar as determinações das APCC cf. Resolução CNE/CP no 2/2002 com os conceitos/conhecimentos/conteúdos pedagógicos e teóricos (a serem) abordados;

19) Compatibilizar o micro ensino com os conteúdos da disciplina no primeiro ano do curso;

20) Compatibilizar o conteúdo da disciplina com à expectativa dos alunos em relação ao desenvolvimento de fluência em LI.

Grupo 3: STT Relativos às dificuldades oriundas de fatores externos

21) Baixa carga horária para aprofundamento de conteúdos;

22) Formação generalista;

23) Falta de conhecimento/interação prévios com os alunos para preparação das aulas;

24) Necessidade de muito tempo para estudo e elaboração conjunta (formadora/monitor) de atividades de reforço.

Grupo 4: STT Relativos às dificuldades oriundas do coletivo de formadores

25) Falta de coesão/coerência nas formas de avaliação propostas.

Fonte: elaborado pela pesquisadora 
Dentre os 25 STT mobilizados pelas formadoras em seus relatos de experiência reflexivo quanto ao SOT -Dificuldades/desafios enfrentados no desenvolvimento do trabalho educacional 14 STT são relativos a desafios provenientes de restrições dos alunosprofessores e encontram-se elencadas no grupo 1 do quadro 1 enquanto os outros 11 STT são distribuídos nos grupos 2,3 e 4 elencando adversidades que se originam em restrições das próprias formadoras para o desenvolvimento do ofício, em restrições externas ou ainda em restrições do coletivo do trabalho, respectivamente. À vista disso, fica evidente, na maioria dos relatos de experiência produzidos, que as formadoras compreendem que são as atitudes negativas ou deficiências de saberes mínimos dos alunos-professores que ocasionam a maior parte das barreiras no desenvolvimento de seu trabalho neste contexto de formação inicial investigado configurando o real de sua atividade (CLOT, 2006), ou seja, aquilo que foi possível de ser realizado independente do que, a princípio, foi prescrito ou planejado.

O estudo ainda pontua que apesar de a entrevista semiestruturada, com cada uma das oito formadoras participantes, reiterar esses desafios elencados no quadro 1 , grupo 1 (STT relativos às dificuldades oriundas dos alunos-professores), o fechamento da maioria dos relatos de experiência reflexivos e mesmo as representações que se formaram sobre o trabalho educacional por meio da entrevista semiestruturada também possibilitaram verificar que as formadoras, de forma geral, perceberam que suas ações têm contribuído para o amadurecimento desses alunos-professores. Este fato é evidenciado no estudo, principalmente, quando a pesquisadora estabelece relações entre as avaliações que a maioria das formadoras teceu com relação aos alunos-professores no início do período de atuação na turma e em seu término. A transição de representações negativas para positivas são explicitadas ao longo do estudo e aqui exemplificadas por meio de dois excertos extraídos da entrevista semiestruturada de duas dentre as oito formadoras participantes, denominadas $\mathrm{F} \mathrm{e} \mathrm{H}$ :

F: Eu percebi assim do início de turma né... Quando começou a disciplina assim até no final... Primeiro parecia assim que eles não tinham muito interesse. [...] Eu percebi nessa turma isto, este crescimento assim, um crescimento assim surpreendente em relação assim de querer buscar mais [...]

H: [...] eles estão amadurecendo eles já estão num processo assim já saíram daquela fase do $1^{\circ}$ ano que é uma questão mais oba já estou na faculdade não agora eles já tem uma visão não tá no $3^{\circ}$ ano mas já assim no período de transição mesmo já estão entendendo que os processos tem que estudar mais tem que discutir mais tem que fazer as coisas então já tem esse processo de 
amadurecimento dentro da questão de você enquanto aluno enquanto trabalho e responsabilidade $[\ldots]$

Embora as formadoras evidenciem esta transição ou amadurecimento dos alunosprofessores, a pesquisadora conclui seu estudo alertando para a necessidade de promover ações que integrem as formadoras das diversas áreas que constituem o curso Letras/Inglês defendendo que contribuições recíprocas dos diferentes campos que compõem a matriz curricular enriquecem a formação inicial de nossos futuros professores. Corrêa defende que, seja qual for o seu contexto de atuação, "um professor não se forma apenas pelas vias acadêmicas", ou seja, através de cursos de formação inicial e continuada, mas, sobretudo, "se forma pelas inúmeras relações interpessoais e profissionais estabelecidas, pelas experiências cotidianas, pelo ambiente familiar e pela convergência entre a teoria e a prática pedagógica" (DINIZ et al, 2005, p.50).

Passamos na sequência à discussão da segunda pesquisa.

\subsubsection{A segunda pesquisa: o trabalho do professor-formador de língua inglesa e a natureza de aprendizagem na educação em pré-serviço}

A pesquisa realizada por Silva teve como objetivo geral investigar a relação entre o trabalho real do professor-formador e suas implicações na natureza de aprendizagem na formação em pré-serviço de uma universidade estadual do estado do Paraná. Para isso, a análise desenvolvida se pautou em documentos oficiais, Planos de Ensino, transcrições de reuniões de área, materiais didáticos adotados e elaborados pelos professores-formadores no decorrer do ano de 2012. Com base no referencial teórico e metodológico do Interacionismo Sociodiscursivo (BRONCKART, 1999; 2004; 2006; 2008, MACHADO; 2004; 2005; 2007, CRISTOVÃO \& NASCIMENTO 2005) e das Ciências do Trabalho, mais especificamente, a Clínica da Atividade (CLOT, 1999/2006) e, sobretudo sob o viés marxista (MARX, 2011). Os participantes da pesquisa foram 7 (sete) professores-formadores da área de língua inglesa lotados no departamento de Letras e estudantes do curso de Letras da instituição. ${ }^{4}$

\footnotetext{
4 Para responder ao objetivo geral da tese, a pesquisa foi delimitada por quatro objetivos específicos, a saber, i. caracterizar a particularidade e singularidade do contexto de pesquisa; ii. identificar os focos de atenção proeminentes em textos produzidos por professores-formadores; iii. investigar os conceitos centrais desenvolvidos em textos produzidos por professores-formadores $\mathrm{e}_{i}$ iv. identificar quais processos psíquicos superiores são potencializados pelo material didático.
} 
Nesse artigo nos restringimos à discussão parcial do objetivo dois da pesquisa, identificar os focos de atenção proeminentes em textos produzidos por professores formadores; considerando unicamente as reuniões de área realizadas no decorrer do ano letivo de 2012 . Como na pesquisa de Corrêa, também nos subsidiamos dos aportes metodológicos do ISD para análise, sobretudo, nesse caso, os SOT e os STT. A identificação de ambos nos auxiliou a refletir sobre os focos de atenção predominantes nas reuniões de área (og reuniões transcritas). A realização dessa análise é justificada à medida que os focos de atenção evidenciam as preocupações, os conceitos e, especialmente os aspectos dados como prioridades no trabalho do professor-formador a partir dos textos produzidos pelos professores-formadores. Eles evidenciam aspectos que subsidiam os direcionamentos que guiam as práticas docentes.

Uma tabulação dos focos de atenção nas reuniões de áreas nos levou a ver que os SOT mais recorrentes, foram, respectivamente: Plano de Ensino (tema predominante em cinco reuniões), exame (diagnóstico) (tema predominante em duas reuniões e segunda maior predominância em uma reunião), livro didático (tema predominante em duas reuniões e segunda maior predominância em uma reunião), metodologia de Ensino (tema predominante em uma reunião e segunda maior predominância em duas reuniões).

Assim, os focos de atenção se voltaram, portanto, para os SOT tidos como maior necessidade e relevância para os professores-formadores, no período da geração de dados: plano de ensino (PE), livro didático (LD), exames (E) e metodologia de ensino (ME). A título de exemplificação da análise realizada, inserimos um excerto da primeira reunião no momento em que as leituras das ementas têm início, ao contemplar o SOT PE:

37. Rı B: gente, vamos começar por qual ementa?

38. M: língua inglesa, pela ordem? [pausa] posso ler o que está aqui? Vamos ver se está igual a da Ana Paula? []

39. B: bom, eh, deixa a Ana pegar o PPP pra gente ver o que está no PPP.

40. M: vamos ver se está igual esse aqui. Leia aí Ana Paula.

No turno 38, a docente Bia lança a questão ao grupo 'vamos começar por qual ementa?'. A leitura das ementas se origina pela necessidade de definição de um ponto de partida, indicado pela pergunta realizada e, na sequência, pela resposta de Marília, ao mencionar 'LI, pela ordem', ou seja, da primeira à quarta série do curso. 
Os SOT se desenvolveram ao longo das reuniões, se alterando e com diferentes níveis de intensidade, criando um movimento dialético que recriamos no gráfico 1:

Gráfico 1: Movimento temático nas reuniões de área.

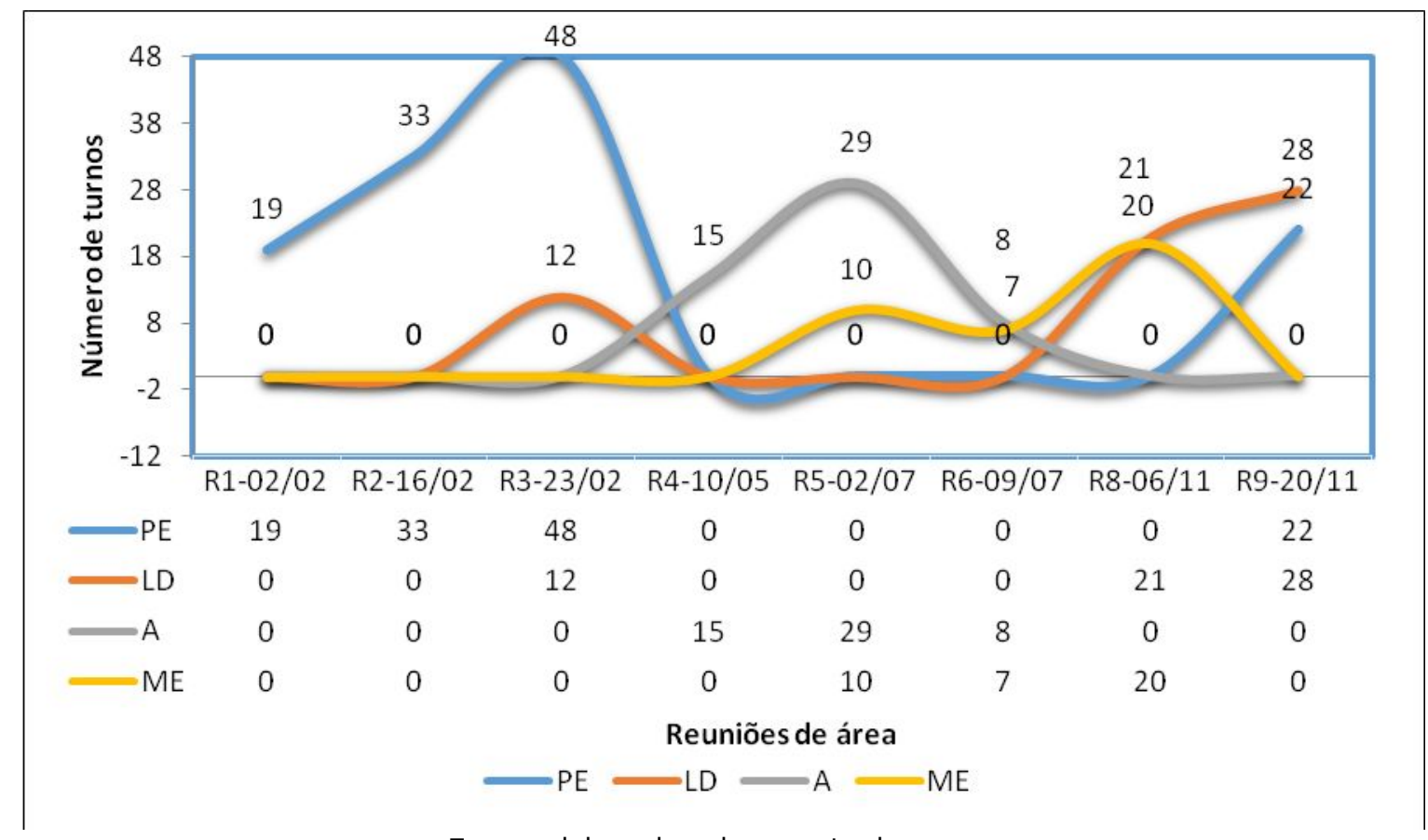

Fonte: elaborado pela pesquisadora

No gráfico 1, os SOT mais recorrentes nas nove reuniões são apresentados. Por ele, podemos visualizar, por exemplo, como o tema $\mathrm{PE}$, representado na cor azul, se inicia na reunião 1 contendo 19 STT, reunião 2 com 33, reunião 3 com 48, desaparecendo entre as reuniões 04 e 08 e, retornando na reunião 09 com 22 STT.

Além disso, ao elaborar esse gráfico, percebemos o movimento que os temas predominantes sofreram de uma reunião para outra e, se tornam visíveis também suas reiterações nas reuniões. Ao analisar cada tema, os recortes realizados em cada reunião se deram por sua inserção ou reiteração a partir das segmentações subtemáticas que os constituem. Os STT de cada SOT têm como recorte somente as reuniões em que eles foram um dos dois temas predominantes. Dessa forma, para o SOT Plano de Ensino, focamos nossa análise nas reuniões 1, 2, 3 e 10. Em relação ao tema metodologia de ensino, reuniões 5, 6, 8; Livro didático, reuniões 3, 8 e 9 e exames, reuniões 4, 5 e 6.

Esses SOT podem ser resumidos em preocupações relacionadas ao processo de ensino e aprendizagem, considerando aspectos do trabalho docente, desde seu 
planejamento até sua transposição em sala de aula. Vemos que um dos elementos do trabalho docente se sobressai: os instrumentos de ensino, sejam eles materiais (tais como o $P E$, o LD), ou mesmo aqueles simbólicos (gênero textual, gramática). Esse conjunto de instrumentos tem como objetivo modificar os modos de pensar de outras pessoas, nesse caso, os modos de pensar do estudante. Essa mediação via instrumentos materiais e psicológicos são parte inerente do trabalho do professor.

Além disso, a articulação revela uma ideologia, de certa forma, comungada entre os professores-formadores, considerando a liberdade de escolhas tidas nesses contextos singular, conforme Silva afirma,

[...] como muito poucos profissionais no mundo, os professores universitários temos o direito assegurado de ler, escrever e ensinar sobre o que der na telha. Ora, se não lemos, escrevemos e ensinamos sobre aquela bibliografia fundamental que eu mencionava (Gilberto Freyre \& Cia.), é porque julgamos que haja coisa melhor a fazer. (SILVA, 2011, p. 17).

Embora haja prescrições do trabalho docente na universidade, o professor goza da oportunidade singular de realizar escolhas sobre o que e como ensinar. Apesar disso, há um paradoxo, pois ideologicamente os docentes se veem arrastados pelas perspectivas dominantes. Ou elas são tidas como atrasadas ou aquelas, do momento atual que deveriam ser a opção adotada.

Essa identificação em todos os conjuntos de dados mostra uma tendência no campo de ensino de língua estrangeira no Brasil. Alguns pesquisadores discutem-nas e analisam como tendências que provém, por exemplo, de documentos oficiais prescritivos no estado do Paraná para o professor da educação básica. Dentre eles, citamos Cristovão (2002), Beato-Canato (2009), que investigaram especificamente o trabalho do professor de língua inglesa em um determinado contexto do Brasil.

Para a formação de professores, (STUTZ, 2012; RIOS-REGISTRO, 2013) a questão é mais complexa, pois no campo da formação, trata-se de formação da força de trabalho e como tal, o alunado precisa ser minimamente competente e flexível para assumir um trabalho cada vez mais precário.

Assim, os focos de atenção em uma particularidade que historicamente se origina em um contexto em que a formação de professores não é prioridade nas políticas públicas e que em seu desenrolar, embora haja conquistas feitas pelos trabalhadores por meio de 
muita luta e engajamento político, ainda é permeado por políticas neoliberais e que, cada vez mais, portanto, intensifica o trabalho do professor-formador, embora em dois momentos, na planificação e na elaboração do Plano de Ensino haja a diversidade entre tendências de ensino normativas e mais contemporâneas como a perspectiva voltada para o texto, como o ensino por meio de gêneros textuais/discursivos e pela abordagem temática.

O professor possui uma autonomia de escolhas, mas ela é sempre relativa, pois depende da particularidade de seu trabalho e também da totalidade que esse trabalho é constituído.

\section{O que as duas pesquisas nos dizem}

Os dados das pesquisas de Corrêa e Silva mostram a preocupação com a tríade didática (Schneuwly, 2004), professor-formador, alunos, objetos do conhecimento em uma relação mediada por ferramentas simbólicas e materiais em um meio constituído social, cultural, política, histórica e economicamente. Nessa relação voltada para o processo de ensino e aprendizagem de ser professor de língua estrangeira ou adicional (nessa caso, inglês), diferentes elementos podem ser reconhecidos como nodais, em especial, alguns diretamente ligados aos vértices do triângulo e aos recursos mediacionais das interações/relações.

No estudo desenvolvido por Corrêa, devido à considerável diversidade e quantidade de STT mobilizados pelas formadoras ao tratar o SOT - Dificuldades/desafios enfrentados no desenvolvimento do trabalho educacional - a pesquisadora conclui que os fatores que ocasionam tais adversidades parecem afetar diferentemente cada uma das formadoras participantes sendo causa de frustração para algumas e/ou de estímulo para busca de soluções para outras. Corrêa ainda defende que parte destas distinções possa ser ocasionada pela especificidade de cada disciplina e, além disto, dado o contexto sociossubjetivo/socioprofissional das oito participantes no que concerne às suas condições díspares de atuação (efetiva, colaboradora, substituta) bem como as diferentes formações e/ou experiências profissionais para docência na disciplina ministrada. No entanto, independentemente deste contexto, segunda a pesquisadora, a maior parte das formadoras $(62,5 \%)$ aponta para a resistência e/ou incompreensão dos alunos quanto aos procedimentos e/ou instrumentos didáticos pedagógicos por elas adotados (Quadro 1, 
grupo 1 -STT 1) indicando que esta é a causa que mais dificulta o trabalho do coletivo de formadoras participantes no processo de formação inicial dos futuros professores. Portanto, parece ser este um dos principais fatos que marcam a experiência desse corpo docente e desencadeia reflexões e ações visando à transposição dessa barreira. Para Corrêa, muitas das dificuldades/desafios das formadoras do contexto investigado enfrentados no desenvolvimento do trabalho educacional, poderiam ser reduzidos se houvesse "assim como se prega aos professores da educação básica, tempo e espaço próprios, em serviço, para analisarem e refletirem suas práticas" de forma interdisciplinar estabelecendo uma "articulação entre disciplinas, conteúdos e práticas" (MATSUOKA, 2012, p. 6).

Na investigação realizada por Silva, os resultados da análise dos textos produzidos pelos professores-formadores revelam um foco de atenção, de um modo geral, no processo de ensino-aprendizagem, ao considerarem aspectos como instrumentos materiais e simbólicos para que esse processo ocorra. De um lado, temos a seleção de alguns instrumentos materiais específicos como pontos de convergência em alguns momentos e, em outros, de divergência.

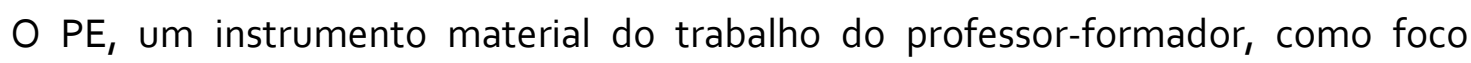
central dos textos, evidenciou tensões, preocupações e conceitos que foram desenvolvidos ao longo das reuniões. A partir dele, outros instrumentos foram tencionados, como é o caso do ensino via gêneros textuais ou via abordagem temática ou ainda possibilitou a emergência de outros SOT, tais como o LD.

O livro didático, que é introduzido timidamente nas reuniões, torna-se relevante nas últimas reuniões do período letivo a tal ponto que culmina na adoção de um LD como piloto para o ensino na disciplina de LI I, a partir de discussões acirradas sobre o conteúdo e a metodologia de ensino (SOT 4) a ser adotada na formação de professores. Nesse segundo ponto, um instrumento semiótico, como o gênero textual se torna a fonte de discussão para a formação inicial e revela representações dos professores-formadores de que ensinar por meio de gênero textual está vinculado ou não a ensinar LI em um curso de formação.

Nesse caso, há uma tensão entre a adoção de um LD que poderia nortear o trabalho de ensino do professor-formador em detrimento da adoção de uma perspectiva metodológica de ensino por meio de gêneros textuais ou vice-versa. 
Por fim, o trabalho do professor-formador é permeado por possibilidades de ações voltadas para a formação e, ao mesmo tempo, é limitado pelas condições materiais e sociosubjetivas em que está inserido.

Ao pensar nas duas investigações, percebemos que alguns projetos poderiam ser comuns entre os dois contextos de ensino devido a algumas características similares na formação inicial em Letras da mesma universidade, mas com especificidades singulares destacando-se, dentre elas, o fato de uma ofertar licenciatura dupla - Letras Português/Inglês - e a outra licenciatura única - Letras/Inglês. Quanto às problemáticas comuns desses dois contextos, algumas intervenções em um plano interinstitucional podem ser constituídas de reflexões sobre a matriz curricular de cada curso e de ações coletivas que poderiam contribuir para a formação do professor em pré-serviço. Uma educação possibilitadora de emancipação integral de um profissional cujo trabalho se dará em intervenções nos modos de pensar e agir das pessoas em constantes interações.

Sem sombra de dúvida, fica clara a necessidade de trabalho coletivo e a discussão sobre a tríade didática para que ações possam ser tomadas com vistas à superação de dificuldades apontadas, desafios a serem vencidos e colaboração em prol de um mesmo fim - o ensino como trabalho tal como concebido por Machado (2004) e, consequentemente, a formação de qualidade.

As pesquisas desenvolvidas e relatadas não só possibilitaram a melhor compreensão dessa atividade educacional, o trabalho do formador de professores, como promove espaço para deliberações e ações coletivas e individuais em espaços diversos, em especial, aqueles investigados.

\section{Referências bibliográficas}

AMIGUES, R. Trabalho do professor e trabalho de ensino. In: MACHADO, A. R. (Org.). O ensino como trabalho: uma abordagem discursiva. Londrina: Eduel, 2004. p.37-53.

BEATO-CANATO, A. P. M. O desenvolvimento da escrita em língua inglesa com o uso de sequências didáticas contextualizadas em um projeto de troca de correspondências. 2009. 307 fls. Tese (Doutorado em Estudos da Linguagem) - Universidade Estadual de Londrina, 2009. 
BRONCKART, J.-P. Atividade de linguagem, textos e discursos: por um Interacionismo Sociodiscursivo. São Paulo: EDUC, 1999/2003/2007/2009.

. Restrições e liberdades textuais, inserção social e cidadania. Conferência inaugural do XIV INPLA. Trad. Ana Raquel Machado, (mimeo). São Paulo, 2004.

Atividade de linguagem, discurso e desenvolvimento humano. $1^{\text {a }}$ ed. Trad. Anna Rachel Machado; Maria Lucia Meirelles Matencio. Campinas, Mercado de Letras, 2006.

O agir nos discursos: das concepções teóricas às concepções dos trabalhadores. $1^{\text {a }}$ ed. Trad. Anna Rachel Machado; Maria Lucia Meirelles Matencio. Campinas, Mercado de letras, 2008.

; MACHADO, A.R. Procedimentos de análise de textos sobre o trabalho educacional. In: MACHADO, A.R. (org.). O ensino como trabalho: uma abordagem discursiva. Londrina: Eduel, 2004. p. 131-161.

CALVO, L. C. S. Reflexões sobre uma comunidade de prática constituída a partir das interações de formadoras de professores de inglês em um grupo de estudos. 2013.191 f. Tese (Doutorado em Estudos da Linguagem) - Universidade Estadual de Londrina. Londrina, 2013.

CLOT, Y.A função psicológica do trabalho. Tradução de Adail Sobral. São Paulo: Vozes, 1999/2006.

CRISTOVÃO, V. L. L. Gêneros e ensino de leitura em LE: os modelos didáticos de gêneros na construção e avaliação de material didático. São Paulo.2002. 263 fls. Tese (Doutorado em Linguística Aplicada e Estudos da Linguagem) - Pontifícia Universidade Católica de São Paulo, São Paulo, 2002.

; NASCIMENTO, E. L. Gêneros textuais e ensino: contribuições do Interacionismo Sociodiscursivo. In: KARWOSKI, A. M.; GAYDECZKA, B. \& BRITO, K. S. (Orgs.). Gêneros textuais: reflexões e ensino. União da Vitória: Kaigangue, 2005. p. 35-60.

DINIZ, J. A. R.; MARIANO, A. L. S.; TANCREDI, R. M. S. P. O Início da docência de uma professora considerada bem sucedida: Apontamentos a partir de relatos orais. In: Formação docente para o ensino superior.VIII Congresso Estadual Paulista sobre formação de Educadores- 2005 UNESP - Universidade Estadual Paulista - Pró-reitora de Graduação, p. 43-51.

FACCI, M.G.D; CRISTOVÃO, V.L.L; BASSO, E.A.; TOGNATO, M.I.R. A Valorização e o Esvaziamento do trabalho Docente: novos percursos a serem percorridos. In: IV Encontro Interdisciplinar da Educação, 2011, Campo Mourão. Anais IV ENIEDUC. Campo Mourão: Universidade Estadual do Paraná, 2011.

FAÏTA, D. Gêneros do discurso, gêneros de atividade, análise da atividade do professor. IN: MACHADO, A.R (org.). O ensino como trabalho: uma abordagem discursiva. Londrina: Eduel, 2004. p.55-80. 
MACHADO, A. R. O diário de leituras: a introdução de um novo instrumento na escola. São Paulo. 1995. Tese (Doutorado em Linguística Aplicada e Estudos da Linguagem) - Pontifícia Universidade Católica de São Paulo, 1995.

MACHADO, A. R. A Perspectiva Interacionista Sociodiscursiva de Bronckart. In: MEURER, J.L.; BONINI, A.; MOTTA-ROTH, D. (orgs.). Gêneros: teorias, métodos e debates. São Paulo: Parábola Editorial, 2005. p.237-259.

Por uma concepção ampliada do trabalho do professor. In: GUIMARÃES, A. M. M.; MACHADO, A. R.; COUTINHO, A. (Org.). O Interacionismo Sociodiscursivo: questões epistemológicas e metodológicas. Campinas, SP: Mercado de Letras, 2007. p. 77-97.

; LOUSADA, E.; BARALDI, G.; ABREU-TRADELLI, L.S.; TOGNATO, M.I.R. Relações entre linguagem e trabalho educacional: novas perspectivas e métodos no quadro do Interacionismo Sociodiscursivo. In: Calidoscópio, v.2, n.2, jul./dez.2004.

; BRONCKART, J.P. (Re-)configurações do trabalho do professor construídas nos e pelos textos: a perspectiva metodológica do grupo ALTER-LAEL. IN: MACHADO, A.R. e colaboradores: CRISTOVÃO, V.L.L.; ABREU-TRADELLI, L.S. (Orgs.) Linguagem e educação: o trabalho do professor em uma nova perspectiva. Campinas, SP: Mercado de Letras, 2009. (Série Ideias sobre Linguagem) p. 31-77.

MARX. K. O Capital: crítica da economia política: livro I. SANT'ANNA, R. (Trad.) 28a. ed. Rio de Janeiro: Civilização Brasileira, 2011.

MATSUOKA, S. Para uma política de formação continuada: a formação do professor formador de professor.XVI ENDIPE - Encontro Nacional de Didática e Práticas de Ensino UNICAMP - Campinas, 2012.

RIOS-REGISTRO, E.S.R. O conto na interface língua, literatura de língua inglesa e formação do professor de língua inglesa: uma proposta mediada pela produção de sequências didáticas. Londrina. 2013. 544 fls. Tese (Doutorado em Estudos da Linguagem) - Universidade Estadual de Londrina, 2013.

SAUJAT, F. Ergonomie de l'activité enseignante et développement de l'experiénce professionnelle. Thése pour le doctorat em Sciences de I'Education, 2002.

. O trabalho do professor nas pesquisas em educação: um panorama. In: MACHADO, A.R (Org.). O ensino como trabalho: uma abordagem discursiva. Londrina: Eduel, 2004. p. 334 .

SILVA, F. L. da. A liberdade sacrificada. IN: RAMPINELLI, W. J.; OURIQUES N. Crítica à razão acadêmica: reflexão sobre a universidade contemporânea. $2^{a}$. ed. revisitada. Florianópolis: Editora Insular, 2011. p. 15-22.

SCHNEUWLY, B. La tache: outil de I'enseignant. Métaphore ou concept? In: DOLZ, J.; THÉVENAZ-CHRISTEN, T, WIRTHNER, M, E SHNEUWLY, B. (eds.) Les tâches et leurs entours en classe de français: Actes du 8éme colloque international de La DFLM (Neuchâtel, 26-28 septembre 2001) (CD-ROM). Neuchâtel: IRDP, 2002. 
SCHNEUWLY, B. Gêneros e tipos de discurso: considerações psicológicas e ontogenéticas. In: Gêneros orais e escritos na escola. SCHNEUWLY, B.; DOLZ, J e colaboradores (Orgs.). ROJO, R.; CORDEIRO, G. S. (Trad.). Campinas, SP: Mercado de Letras, 2004. p. 21-39.

STUTZ, L. Sequências didáticas, socialização de diários e autoconfrontação instrumentos para a formação inicial de professores de inglês. Londrina. 2012. 388 fls. Tese (Doutorado em Estudos da Linguagem) - Universidade Estadual de Londrina, 2012.

VYGOTSKY, L.S. A formação social da mente. São Paulo: Martins Fontes, 1978.

A construção do pensamento e da linguagem. BEZERRA, P. (Trad.) 2a. Edição São Paulo: Editora Martins Fontes, 2009.

\footnotetext{
' Alessandra Augusta Pereira DA SILVA - Docente do colegiado de Letras da Unespar, campus de Campo Mourão. Doutoranda, ex-bolsista de doutorado sanduíche pela CAPES com estágio realizado na Universidade de Genebra sob a orientação do prof. Dr. Bernard Schneuwly e bolsista da FAP no Programa Estudos da Linguagem da Universidade Estadual de Londrina sob a orientação da profa. Dra. Vera Lúcia Lopes Cristovão. alessandrafecilcam@yahoo.com.br
}

ii Francini Percinoto Poliseli CORRÊA - Docente do colegiado de Letras da Unespar, campus de Apucarana. Doutoranda no Programa Estudos da Linguagem da Universidade Estadual de Londrina sob a orientação da profa. Dra. Vera Lúcia Lopes Cristovão. francinicorrea@yahoo.com.br

iii Vera Lúcia Lopes CRISTOVÃO - Docente do departamento de Letras Estrangeiras Modernas e membro permanente do Programa de Pós-Graduação em Estudos da Linguagem, da Universidade Estadual de Londrina. Bolsista de produtividade em pesquisa do CNPq. veracristovao@gmail.com

Recebido em 30/06/2015 Aceito em 30/07/2015 